\title{
Postgraduate Supervision in the Philippines: Setting the Research Agenda
}

\author{
Angelito Calma \\ University of Melbourne, Australia
}

\begin{abstract}
This paper reviews the literature on postgraduate supervision by examining recent issues, approaches and perspectives. It highlights supervision as a professional practice where the supervisor is seen as one who must be a reflective practitioner. It also highlights strong intertwining between this field and the literature on professional practice. Elements of the supervisory process that take into consideration candidate-, supervisor-, and institutionrelated variables are proposed as areas for possible inquiry. Finally, the many areas for research and proposed methodologies are explored.
\end{abstract}

Postgraduate supervision in higher education institutions increasingly plays an important role particularly in ensuring quality research work. Supervision has become an increasingly demanding role for supervisors because they need to lead the candidates towards the successful completion of their theses. This puts upon supervisors the need to cope with the demands of effectively practicing their role as research supervisors. The practice of supervision is an evolving field of interest not only for supervisors and candidates but also for other stakeholders who wish to examine it. This paper seeks to review the existing literature in this area, particularly the different perspectives and approaches used. It also seeks to highlight the roles of practitioners as well as their impact on the lives of candidates.

\section{About postgraduate supervision}

Postgraduate supervision adopts the British and Continental system wherein research higher degree students work under a supervisor or supervisors (Heath, 2002). The primary objective of this is to ensure that the candidates receive the needed support and expert help to successfully complete their thesis or dissertation papers. The supervisor ensures, that among others, expertise, time, feedback, support, commitment, and allotted working space are given to the candidates. The candidates must also possess attributes suitable for postgraduate study as well as develop the necessary skills to undergo research in acceptable standards during the process. Supervision is an essential component of postgraduate study and is becoming an important research area (Wisker, Robinson, Trafford, Warnes, \& Creighton, 2003). Note however that postgraduate supervision is different from clinical supervision or practicum supervision. Clinical supervision is for counsellingrelated professions and is mostly carried out in disciplines such as clinical psychology, counselling, human services, and social work (see Degeneffe, 2006). Also associated with counselling and psychotherapy, practicum supervision, on the other 
hand, trains students to acquire counselling skills (see also Skinstad, 1993).

\section{The supervisor as a reflective practitioner}

Supervision issues pose challenges for supervisors in administering the exchange between them and the candidates. But beyond ensuring successful completion, Lee and Williams (1999) point out that one important objective is the creation of a new identity among the graduate students. As Green and Lee (1999, cited in Malfroy \& Yates, 2003) put it, "what is at stake in doctoral work and postgraduate supervision, over and beyond the much vaunted contribution to knowledge, is precisely the (re)production of an intelligible academic identity - a certain kind of (licensed) personage (p. 127)." The supervisor must reflect on his/her role as not only as one who provides support but also one who is a key person responsible in producing a new identity in the process. Schön (1991, p. 32) also indicated that the supervisor as a reflective practitioner must be somebody who has "claim to extraordinary knowledge" (using Everett Hughes' terms) and has a "license to determine who shall enter his[/her] profession". Heath (2002, p. 127) further argues that successful completion of postgraduate study (particularly $\mathrm{PhD}$ ) relies heavily on supervision since the supervisor has the prime responsibility in "creating [this] new identity of the licensed academic." Thus, supervisors must have research knowledge and related skills, as well as management and interpersonal skills (Beasley, 1999) as necessary components of their practice. Another important discussion found in the literature is role choice and management. The role of the supervisor is becoming more complex and challenging because there is the need to balance several roles to adapt to different candidates' needs and personalities (Vilkinas, 2002). At times, supervision is regarded as a form of 'discipleship' (Johnson, Lee, \& Green, 2000) or 'apprenticeship' and 'therapeutic counselling' (Sayed, Kruss, \& Badat, 1998).
Ideally, the supervisor is not someone who merely assumes the role because he or she was selected by a candidate, or someone who assigns him or herself out of convenience. Unfortunately, with the growing number of candidates who need to be supervised, some supervisors may be forced to commit themselves to candidates whose research interests differ from theirs. In addition, it may also be possible that some supervisors lack the required expertise to direct the candidates' research. Further, even In instances where supervisors have such expertise, the transfer of such may still not happen due to limited contact hours or other reasons. 'Claim to extraordinary knowledge' is a serious special authority that requires commitment to such authority. This is where the word 'profess' (e.g. in professor) becomes meaningful because as a practitioner of such profession, there must be a claim to something of which the supervisor is knowledgeable. This also adds meaning to Schön's idea of belongingness to a community of practitioners where practitioners share similar expert skills or knowledge in particular fields.

From this, the supervisor as a reflective practitioner must be critical about two things: the profess-ion, and the practice of that profession. The supervisor must be fully aware that supervision as a profession is not simply an extension of teaching work but is also an avenue to train future practitioners in the actual community to which they will eventually belong. The practice of profession refers to experiences in the conduct of activities related to such profession that together make up the know-how of the practitioner. Beckett \& Hager (2002b) aptly describes this know-how as 'a type of knowing what to do in practice that is evident in various intentional actions' (p. 5). This does not only pertain to the techne-the 'hard skills' required in supervision such as statistics and research skills, but also to the tacere-the 'soft skills' that characterize embodied tacit knowledge. 'Knowing what to do in practice', in this case, pertains to the challenging reproduction, manipulation, and application of both the techne and the tacere during supervision. 
Supervision's failures or successes are a result of experiences characterized by expressions such as 'Supervision was doing well,' 'I don't know how she did it but the candidate pulled it through,' 'He left everything to me and now I'm lost,' or 'I learned so much from my supervisor despite less supervision'. Essentially, the practice of supervision refers not only to 'knowing what' and 'knowing how' but also 'knowing why' that represent the appropriate judgments supervisors make during 'hot action' (Beckett \& Hager, 2002b)—referring to the practitioners' 'processes and acts of judgment endemic to everyday experiences at work' (p. 10) — and the required sensitivities in those 'judgements-in-context' (Beckett 2004, p. 499). I find that there are also strong connections between supervisors' field of practice and Schön's (1987, cited in Beckett \& Hager, 2002a) metaphor of the swamp and the high ground:

On the high ground, manageable problems lend themselves to solution through the application of research-based theory and technique. In the swampy lowland, messy, confusing problems defy technical solution. The irony of this situation is that the problems of the high ground tend to be relatively unimportant to individuals or society at large, however great their technical interest may be; while in the swamp lie the problems of greatest human concern. The practitioner must choose. (p. 3)

Making sense of this 'messy, confusing problems' that supervision brings, the supervisor as a practitioner is faced with educative experiences available for reflective thinking and action though they may be seen as otherwise everyday ordinary experiences of meetings between them and the candidates. Thus, supervisors as reflective practitioners must go beyond the desired outcomes of licensing the academic with the necessary research and technical skills and also learn the intricacies of the conduct of their profess-ion as well as be reflective of the 'swampy' experiences and judgements that are embedded in the practice of their profession.

\section{The literature of the practice:}

\section{Some issues, approaches, and perspectives}

Current researches in postgraduate supervision include examination of frameworks for doctoral education, mapping the development of new research programs responsive to the needs of the economy, surveys on students' satisfaction with programs or supervision, use of students' evaluation to benchmark universities (see Marsh, Rowe, \& Martin, 2002), and frameworks for postgraduate supervision (see Zhao, 2003) or evaluation (see Zuber-Skerritt \& Roche, 2004). The literature on evaluation of postgraduate supervision mostly discusses the $\mathrm{PhD}$ process and refers to supervisors' experiences with international students, such as those from universities in Africa, Australia, Singapore, New Zealand, United States and the United Kingdom. However, there seems to be little research on how extensively it is practiced. With this I believe that there's a need to explore the practice of supervision and understand the complexities during the process. There is a lot of knowing what but less of knowing how and knowing why with reference to the understanding of the epistemologies of practice. The latter two are essential areas of research that can provide us details of the transfer of technical skills, the tacitness of knowledge (e.g. when a candidate says 'she's the best supervisor I had'), the richness of the experience, and the judgments made by the supervisor during supervision. Most research focussed on the outcomes rather than the processes, which I believe are also worth examining.

There are a few issues discussed in the literature that present the complexities of supervision. First, there is a strong push for universities to legislate postgraduate supervision (Malfroy \& Yates, 2003) and to consequently draft and implement policies (i.e., Codes of Practice, Guidelines for Thesis Supervision) in order to institutionalise it. Second, the level of access to rich sources of data is also 
seen as essential (i.e., online databases). Third, competency in the English language (Scheyvens, Wild, \& Overton, 2003) must also be part of the candidates' larger set of skills. Fourth, there exists a mismatch between students' expectations and learning and research culture (Wisker et al., 2003). In writing about the autobiography of a former $\mathrm{PhD}$ student in the United Kingdom, Johnson et al., (2000) narrate that students may feel neglected, abandoned, and indifferent during the process and wondered why 'isolation' was necessary. Other issues such as family concerns (e.g. accommodation, child care), female students' needs, time to complete the degree, scholarships and other funding commitments, full-time or parttime study, degree, scale and kind of research undertaken (research relating to teaching, research integrating theory and practice [e.g. health practitioners], and research relating to less-theoryand-practice professions), personality, subject of the research, gender, age, cultural differences, and stages of student's work also affect the nature of supervision (Scheyvens et al., 2003; Wisker et al., 2003). Connell (1985, cited in Malfroy \& Yates, 2003) argues that the two important aspects of postgraduate supervision are (1) providing a curriculum for research, and (2) providing a rich research environment for the

\section{Table 1}

\section{Approaches \& Perspectives on Postgraduate Supervision}

\begin{tabular}{|c|c|c|c|}
\hline Areas & Proponents & Foci & Objectives \\
\hline $\begin{array}{l}\text { Epistemologies of } \\
\text { supervisory practice }\end{array}$ & $\begin{array}{l}\text {-Johnson, Lee, \& Green } \\
(2000) \\
\text {-Lee \& Williams (1999) }\end{array}$ & $\begin{array}{l}\text { Discussed the } \\
\text { underlying assumptions } \\
\text { and tenets of supervision }\end{array}$ & $\begin{array}{l}\text { - To transform the } \\
\text { candidate into a } \\
\text { 'licensed academic' }\end{array}$ \\
\hline $\begin{array}{l}\text { Evaluation of } \\
\text { supervision }\end{array}$ & $\begin{array}{l}\text {-Marsh, Rowe, \& Martin } \\
\text { (2002) }\end{array}$ & $\begin{array}{l}\text { Focus on the } \\
\text { effectiveness of existing } \\
\text { policies and practices }\end{array}$ & $\begin{array}{l}\text { - To use evaluation } \\
\text { results for policy } \\
\text { decisions and improve } \\
\text { practices }\end{array}$ \\
\hline $\begin{array}{l}\text { Examination of } \\
\text { candidate's } \\
\text { experiences }\end{array}$ & $\begin{array}{l}\text {-Wallace (2003) } \\
\text {-Wisker et al. (2003) }\end{array}$ & $\begin{array}{l}\text { Professional, personal, } \\
\text { family challenges and } \\
\text { experiences }\end{array}$ & $\begin{array}{l}\text { - To understand } \\
\text { candidates as learners } \\
\text { with unique and diverse } \\
\text { needs }\end{array}$ \\
\hline Role expectations & -Vilkinas (2002) & $\begin{array}{l}\text { Adaptive roles } \\
\text { supervisors need to take }\end{array}$ & $\begin{array}{l}\text { - To inform supervisors } \\
\text { whose job requires } \\
\text { differing roles }\end{array}$ \\
\hline $\begin{array}{l}\text { Aspects of } \\
\text { successful } \\
\text { supervision }\end{array}$ & $\begin{array}{l}\text {-Beasley (1999) } \\
\text {-Connell (1985, cited in } \\
\text { Malfroy \& Yates, 2003) } \\
\text {-Scheyvens et al. (2003) }\end{array}$ & $\begin{array}{l}\text { Postgraduate research } \\
\text { students' attributes; } \\
\text { supervisors' attributes }\end{array}$ & $\begin{array}{l}\text { - Supervisors and } \\
\text { candidates need to } \\
\text { possess certain } \\
\text { attributes }\end{array}$ \\
\hline $\begin{array}{l}\text { Frameworks for } \\
\text { supervision }\end{array}$ & $\begin{array}{l}\text {-Zhao (2003) } \\
\text {-Vilkinas (2002) }\end{array}$ & $\begin{array}{l}\text { Zhao sees the } \\
\text { supervision } \\
\text { as'knowledge } \\
\text { management' Vilkinas } \\
\text { sees supervisors as } \\
\text { managers with roles to } \\
\text { play. }\end{array}$ & $\begin{array}{l}\text { - Supervisors' practice } \\
\text { must make connections } \\
\text { with management } \\
\text { theories }\end{array}$ \\
\hline
\end{tabular}


development of student and staff. Zhao (2003) also argues that a nurturing culture among universities is a requisite. English and language literacy skills (McClure, 2001), adaptability to new learning environments, provision for social support, especially during the adjustment period during the student's postgraduate experience, accommodation and childcare facilities (Scheyvens et al., 2003) are also seen as essential. All these impact on the supervisor's sense of sensitivity-in-practice, and equally on the candidate's acknowledgment of the life of a postgraduate.

So far, the approaches and perspectives found in the literature generally fall on (1) epistemologies of supervisory practice, (2) candidates' evaluation of supervision, (3) examination of candidate's experiences, (4) role expectations, (5) aspects of successful supervision, and (6) frameworks for supervision. However, there seems to be a need for a framework to guide and equip supervisors as they carry out their duties and responsibilities (please refer to Table 1).

From the literature, I came up with supervisor-related variables that are essential for practitioners in the field of postgraduate supervision and just as important for researchers to examine. These are, among others: area expertise, guidance, management skills, adaptability, research workload, research track record, and interpersonal communication. Area expertise refers to the skilful application of a specialized knowledge (discipline-specific know how). In supervision, this extends beyond the techne and gradually develops through practice and experience. Guidance provides for direction and advice to make intelligent decisions, appropriate judgments-in-context, or courses of action. Guidance in the context of the supervisor does not mean turning the wheel in behalf of the candidate, or providing a deeply attached support to lead the candidate to an intended decision, course of action, or a future state. Much of postgraduate work is building candidates' decision making skills based on independent inquiry. Thus, guidance should be able to develop among the candidates a sense of autonomy-one 'generic skill' (Hager, Holland, \& Beckett, 2002, p. 3) important in postgraduate study. Management skills are the skills related to the effective utilization of resources (e.g. time, space) to meet desired outcomes (e.g. successful supervision, successful candidate's completion). One of the end results of effective management should be to produce a licensed academic who is suitably part of the community of practitioners. In essence, supervisors act as managers in an enterprise (see also Vilkinas, 2002) and that requires effective management of material and human resources. Adaptability refers to effective adjustments of pre-planned actions to meet changing priorities and circumstances. During the supervision process, plans to not always push through; thus, a supervisor's adaptation to varying circumstances allow them to reframe their relational strategies with candidates as well as make adjustments to suit competing demands. Research workload and the supervisor's track record, referring to their pressing research work and their established research career, will also be examined in relation to their likely effects on supervision. Finally, interpersonal communication is a social relationship contract engaged by and between supervisors and candidates. This interpersonal relationship is that which provides effective feedback channels in personal and academic matters. Loose interpersonal links may hinder success but open and collaborative dialogues may help.

The candidate as a learner and a reflective scholar, on the other hand, must also possess certain attributes that best suit him or her to postgraduate study. Hager et al., (2002) posit that there are pertinent generic skills needed for postgraduate study and further conclude that these have effects on postgraduate pedagogy and supervision. Autonomy, critical thinking, communication skills, and research skills are undoubtedly some attributes necessary for postgraduate students. These generic skills must 


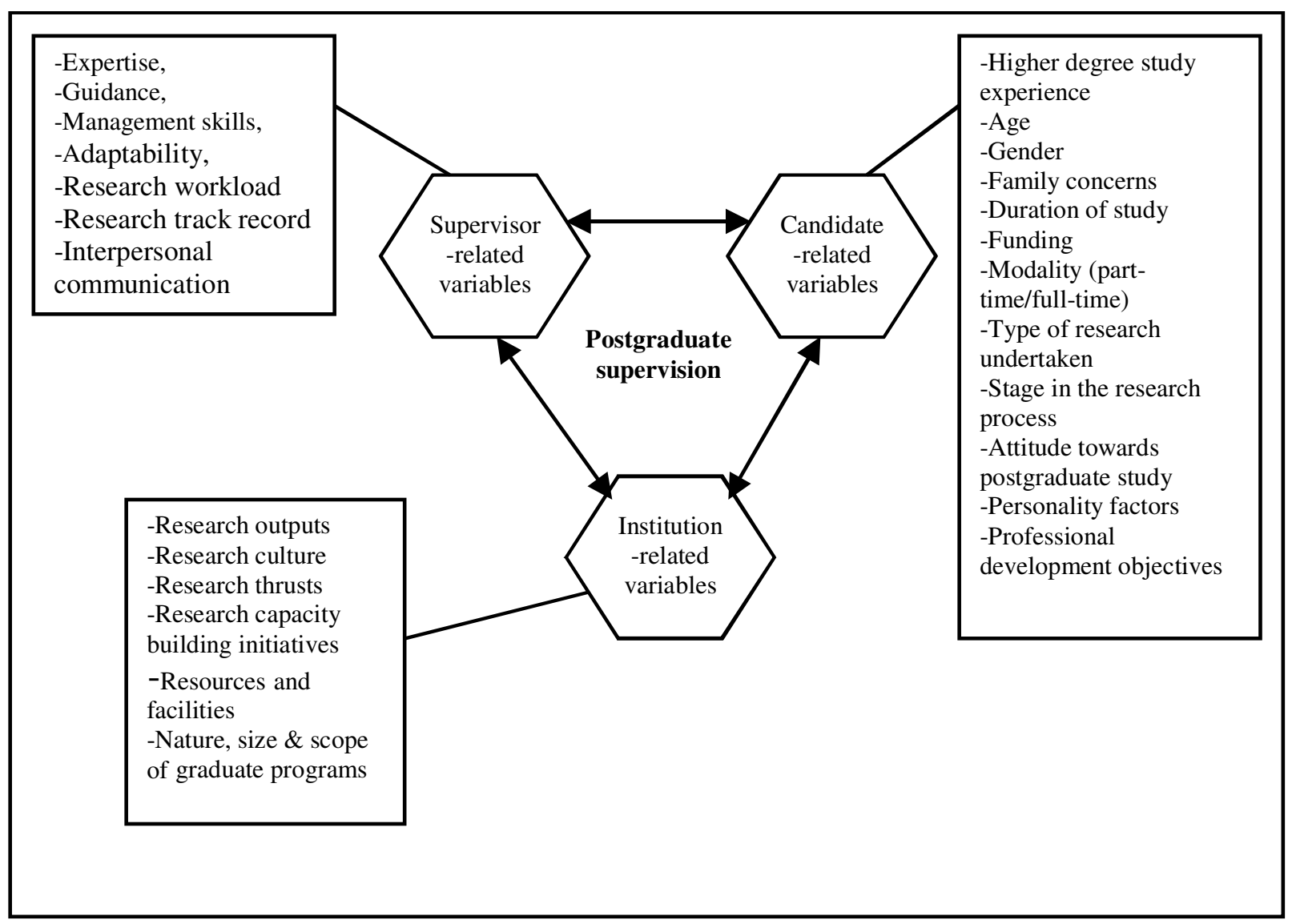

Figure 1. Key variables associated with postgraduate supervision

also reflect their employability (Beckett, 2004) which I refer not only to their career growth with respect to capitalizing on their degrees to advance them in their organizations but also to prepare them as catalytic participants in a wider production, dissemination, and application of research to influence policy and better outcomes.

I have also outlined some candidate-related variables from the existing literature, which may be of interest to some scholars as possible areas of inquiry. These are, among others: higher degree study experience, age, gender, family concerns, duration of study, funding, modality (part-time/full time), type of research undertaken, stage in the research process, attitude towards postgraduate study, personality, and professional development objectives. If we are to examine the practice of supervision, supervisors and candidates are not the only players; rather, the institution where they belong also plays a role. Thus, I came up with institution-related variables: research outputs, research culture, research thrusts, research capacity building initiatives, resources and facilities, and nature and size of graduate programs.

These three groups of variables form the ways in which we direct our research in better understanding the issues associated with supervisory practice. Future research can examine this wholly or investigate a single or few variables of interest. Perhaps, it is best to describe this in Figure 1.

\section{Supervision and postgraduate study in the Philippines}

In most universities offering postgraduate studies, the term 'graduate studies,' referring to post-baccalaureate studies, is more commonly 
used. Since the term 'postgraduate' is used in the literature and elsewhere in good currency, this term is used in this paper as referring to higher degrees beyond a bachelor's degree. Postgraduate study in the Philippines encompasses certificates, diplomas, masters, and doctorate degrees. Certificate or diploma programs are specialized courses with short periods of study. Masters (or Masteral) degrees are usually offered as either a thesis (coursework and research components) or non-thesis degrees (coursework only). In many instances, the postgraduate student is expected to pass a comprehensive exam (written, oral, or a combination of both) for non-thesis degrees or a research work for thesis degrees. Doctoral degrees are also generally completed by way of a comprehensive exam or a dissertation paper or a combination of both. Postgraduate students are expected to attend classes internally or as arranged; and in the latter part of their studies, Masters and doctoral students work with a supervisor or supervisors on their theses or dissertation papers. The graduate schools are responsible for the delivery of these higher degree studies in a variety of disciplines, timetables, schemes, and modalities, attracting graduate students of various profiles academic, industry, professional, or otherwise. Particularly over the past years, higher education institutions have attracted international students, mostly from other parts of Asia, for postgraduate study and this adds to the complexity of supervision as well.

Here are some noted observations during supervision and postgraduate study in the Philippines. Normally, only one supervisor is assigned to each candidate and often a mismatch exists between the candidate's topic and the supervisor's expertise. In some cases, only fulltime faculty members are allocated to these candidates. Most PhD courses have a coursework component, and candidates then take the comprehensive exam, if any, and submit a research proposal for consideration. After which dissertation writing starts. This is quite different in most countries where a search for a suitable supervisor and submission of a research proposal are the requisites for entry into university so that appropriate resources can be planned for allocation (for example, a work space, supervisor's availability, and so on). Products of research by postgraduates sometimes lack connections with the industry and are mostly disseminated within local libraries or publications. Some candidates view the thesis or dissertation simply as a necessary requirement to gain a degree and not as a 'licensing' exercise for further research contributions in their fields of inquiry and practice. The nature of supervision is one that can be likened to 'mentoring' or 'advising' where the work of the supervisor is to check each part of the candidate's work and provide input and comments. However, some supervisors have little or no experience in research and may have little or no publication at all.

There are certain practices I observed that are contradictory to what I found in the literature mentioned above. I outline them below:

1. Lack of area expertise among supervisors

2. Supervisor-to-candidate mismatch

3. Resource allocation problems

4. Thesis/Dissertation submission is seen as an end in itself; and

5. Supervision is 'weak'

These of course affect the whole supervisory practice and expectations of graduates to be 'truly licensed academics.' The supervisor as a reflective practitioner, in this case, must be aware that his or her role is an essential part of the life of the candidate and insufficient guidance can lead to unscholarly and inapplicable research work. A supervisor should be able to foresee that if their assignment to a candidate is out of convenience, that if their interests do not match that of the candidates', that if they lack technical expertise, greater problems may be expected to arise. One important aspect of supervision is area expertise and there are no better persons to 'license' candidates than 'licensed' academicians themselves. This 'license to license' can be gained through research experience and training, which 
are essential features of a supervisor's portfolio of expertise. Cryer and Mertens (2003) even suggest that a training program is necessary for supervisors to equip them for the job. Such training need not only be about managing candidates but most particularly research training skills. This validates the essential meaning of generic skills mentioned earlier that supervisors also must possess.

\section{Setting the research agenda}

The practice of supervision is not an easy task and it encompasses roles, responsibilities, attributes, skills, and competences needed by supervisors. Corollary to that are environment and culture factors that intertwine in the process. The literature is scarce in providing documented cases and empirical researches that describe effective practices in supervision. It also lacks discussion on the use of other research methodologies in exploring the phenomenon. With this it is recommended that further studies be done on the following areas:

1. Best practices in supervision

2. A framework for learning skills by postgraduates

3. Case stories

4. Exploration of the differences between Masters and $\mathrm{PhD}$ candidates, between doctorate and $\mathrm{PhD}$, between subject disciplines, between geographical contexts

5. The effects of culture on supervisory relationships

6. The effects of supervision on candidates' works

7. Phenomenological approaches in describing not what supervision is but how it was it experienced and what it meant to them

Along with these, the proposed agenda for research to deepen our understanding of supervision as a professional practice should focus on:
1. Direct observations of supervisors during 'hot action'. This refers to ways in which they make decisions to influence the work of the candidate. This can be likened to a consultation with a doctor wherein the doctor takes all forms of information and processes them to prescribe medication if needed. The hot action of supervision then is the face-toface interaction where the supervisor makes judgment on the basis of information presented by the candidate (e.g. the candidate's draft, generic skills, motivation).

2. Interviews with supervisors. Separate individual and group discussions must be done among supervisors. Of interest would be their perceptions of supervision, problems encountered, solutions generated, nature and types of judgments made, their perceptions of their practice, and reflection strategies undertaken.

3. Interviews with candidates. Both individual and group interviews with candidates can also be done. Of interest to researchers would be (apart from the literature) their perceptions of their practice as researchers, research relevant to their work, and future career options.

4. Discourse analysis. This includes examining the discourse between supervisors and candidates during 'hot action' and what inferences can be made on the attempts to guide the candidates toward scholarly work.

5. Examination of the theory-of-action. The point here is to examine both espoused theory and theory-in-use (Argyris \& Schön, 1996; Smith, 2001; Carrick, 1998). In a less critical sense, espoused theory is the theory behind what supervisors say while theory-in-use is the theory behind what supervisors do. An examination of what is believed that supervisors are doing (some general 
assumptions of their practice) and what they actually say they are doing against what they actually do is a critical point.

With this, it is hoped that a deeper examination of the practice of supervision will be unravelled and possibly answer some fundamental questions we have been raising for a long time now (particularly in the Philippine setting) such as: Why are research outputs not as scholarly as expected? Why are products of research less disseminated? Why do supervisors fail in producing the academic? Why do candidates produce less scholarly research? What kinds of infrastructure and support systems make supervision a success? What kinds of knowing-in-action and reflection-in-action circumstances arise? What are the necessary techne and tacere skills needed for effective supervision and postgraduate study? Undoubtedly, what I have examined in the literature above on how far we have theorized the epistemologies of the practice of supervision as well as the empirical researches in this field cannot fully answer these questions. We can broaden our understanding of postgraduate supervision not only by examining its nature but also by documenting cases on how this actually happens in the 'swamp,' which is radically different from the descriptive nature of understanding this phenomenon. Perhaps, the real picture of why research quality and relevance is far to reach lies in those experiences and judgments-in-context waiting to be seen.

\section{CONCLUSION}

As higher education pushes for quality, accountability, excellence, and relevance, there is a need to rethink the importance of supervision. This paper highlights the fact that supervision is a serious role and that 'licensing' is a necessary feature of a supervisors' partnership with a candidate. It makes an attempt to illustrate observed dilemmas and pushes some inquiry areas to further examine the supervisory process by proposing methodological approaches.

\section{REFERENCES}

Argyris, C., \& Schön, D. A. (1996). Organizational learning II. Reading, MA: Addison-Wesley.

Beasley, N. (1999). Staff development to support research supervision, In Wisker, G. and Sutcliffe, N. (Eds.), Good practice in postgraduate supervision (Vol. SEDA paper 106), Staff and Educational Development Association.

Beckett, D. \& Hager, P. (2002a). Life, Work, and Learning: Practice in Postmodernity (Ch. 1). London: Routledge.

Beckett, D. \& Hager, P. (2002b). Life, Work, and Learning: Practice in Postmodernity (Ch. 2). London: Routledge.

Beckett, D. (2004). Embodied competence and generic skill: the emergence of inferential understanding. Educational Philosophy and Theory, 36(5), 497-508.

Carrick, J. (1998). Donald Schön's presentation 'Educating the reflective practitioner' to the 1987 meeting of the American Educational Research Association Washington, D.C. Retrieved October 10, 2006 from http:// educ.queensu.ca./ ar/schon87.htm

Cryer, P., \& Mertens, P. (2003). The PhD examination: support and training for supervisors and examiners. Quality Assurance in Education, 11(2), 92-99.

Degeneffe, C. E. (2006). Clinical supervision in the helping professions: A practical guide. Rehabilitation counselling bulletin, 50(1), 5960.

Hager, P., Holland, S., \& Beckett, D. (2002). Enhancing the learning and employability of graduates: the role of generic skills. Position paper no. 9 Business-Higher Education Round Table Melbourne.

Heath, T. (2002). A quantitative analysis of PhD students' views of supervision. Higher education research and development, 21(1), 41-53.

Johnson, L., Lee, A., \& Green, B. (2000). The $\mathrm{PhD}$ and the autonomous self: gender, rationality 
and postgraduate pedagogy. Studies in Higher education, 25(2), 135-147.

Lee, A., \& Williams, C. (1999). Forged in fire: narratives of trauma in $\mathrm{PhD}$ supervision pedagogy. Southern Review, 32(1), 6-26.

Malfroy, J. \& Yates, L. (2003). Knowledge in action: Doctoral programmes forging new identities. Journal of Higher Education Policy and Management, 25(2), 119-129.

Marsh, H. W., Rowe K. J., \& Martin, A. (2002). Phd students' evaluations of research supervision. The Journal of Higher Education, 73(3), 313-348.

McClure, J. (2001). Developing language skills and learner autonomy in international postgraduates. ELT Journal, 55(2), 142-148.

Sayed, Y., Kruss, G., \& Badat, S. (1998). Students' experience of postgraduate supervision and the University of the Western Cape. Journal of Further and Higher Education, 22(3), 275-285.

Scheyvens, R., Wild, R., \& Overton, J. (2003). International students pursuing postgraduate study in geography: impediments to their learning experiences. Journal of Geography in Higher Education, 27(3), 309-323.

Schön, D. (1991, orig 1987). Educating the reflective practitioner (Ch 2). San Francisco: Jossey-Bass.
Skinstad, A. H. (1993). Practicum supervision in Norway and the United States. Journal of counselling and development, 71(4), 406408.

Smith, M. K. (2001). Cris Argyris: theories of action, double-loop learning, and organizational learning. Retrieved on October 12 from http://www.infed.org/thinkers/ argyris.htm

Vilkinas, T. (2002). The PhD process: the supervisor as manager. Education and Training, 44(2), 129-137.

Wallace, S. (2003). Figuratively speaking: Six accounts of the $\mathrm{PhD}$ viva. Quality assurance in education, 11(2), 100-108.

Wisker, G., Robinson, G., Trafford, V., Warnes, M., \& Creighton, E. (2003). From supervisory dialogues to successful PhDs: strategies supporting and enabling the learning conversations of staff and students at postgraduate level. Teaching in Higher Education, 8(3), 383-397.

Zhao, F. (2003). Transforming quality in research supervision: A knowledge-management approach, Quality in Higher Education, 9(2), 187-197.

Zuber-Skerritt, O., \& Roche, V. (2004). A constructivist model for evaluating postgraduate supervision: A case study. Quality Assurance in Education, 12(2), 82. 